\title{
Polymerization of Bicyclic Acetals. IX. Cationic Polymerization of 4-Bromo-6,8-dioxabicyclo[3.2.1]octane ${ }^{\dagger}$
}

\author{
Masahiko OKADA, Hiroshi Sumitomo, and Akira SumI \\ Faculty of Agriculture, Nagoya University, \\ Chikusa-ku, Nagoya 464, Japan.
}

(Received July 23, 1981)

\begin{abstract}
Polymerization of the two stereoisomers (1a and 1e) of 4-bromo-6,8dioxabicyclo[3.2.1] octane was carried out in methylene chloride at different temperatures ranging from -90 to $0^{\circ} \mathrm{C}$. Antimony pentafluoride, antimony pentachloride, and trifluoromethanesulfonic acid were found effective for the homopolymerization of the equatorially substituted isomer (1e). Isomerization of $1 \mathrm{e}$ to the axially substituted counterpart (1a) occurred during the polymerization at $-30^{\circ} \mathrm{C}$ or above to provide a copolymer of $1 \mathrm{e}$ and $1 \mathrm{a}$, especially when trifluoromethanesulfonic acid was used as an initiator. ${ }^{13} \mathrm{C}-\mathrm{NMR}$ analysis of the resulting polymers disclosed that the polymer of 1e prepared at $-90^{\circ} \mathrm{C}$ entirely consisted of a structural unit ( $\alpha$-form) in which the exocyclic acetal oxygen atom was axially oriented to the tetrahydropyran ring in a repeating unit. With the rise in polymerization temperaure, the fraction of the other structural unit ( $\beta$-form) in which the exocyclic acetal oxygen lies in the equatorial position of the tetrahydropyran ring increased appreciably. Polymerization of stereoisomer mixtures of 1a and 1e was induced even with boron trifluoride etherate which is an ineffective initiator for the homopolymerization of 1 e. Irrespective of the reaction conditions, the relative reactivity of $\mathbf{1 a}$ was higher than that of 1 . The difference in the reactivity between the stereoisomers are discussed in comparison with those of 6,8dioxabicyclo[3.2.1]octane and anhydrosugar derivatives having the identical skeleton.

KEY WORDS Cationic Polymerization / Ring-Opening Polymerization /

Bicyclic Acetal / 4-Bromo-6,8-dioxabicyclo[3.2.1]octane / Stereoisomer /

Isomerization /
\end{abstract}

Cationic polymerization of bicyclic acetals possessing a tetrahydropyran ring has been one of the main subjects of our investigation, since it is not only of great help in elucidating the stereochemistry and mechanism of the ring-opening polymerization of cyclic acetals ${ }^{1-8}$ but also provides useful precursors for the synthesis of structurally well-defined polysaccharide analogues having physiological activities. $^{9-12}$ As a continuation of the series of studies along this line, the cationic polymerization of 4-bromo-6,8-dioxabicyclo[3.2.1]octane was investigated for the following two reasons: First, 4bromo-6,8-dioxabicyclo[3.2.1]octane which is readily prepared from 3,4-dihydro- $2 H$-pyran-2-carbaldehyde (acrolein dimer) consists of two stereoisomers, 1a and 1e, having a bromine atom in the axial

\footnotetext{
${ }^{\dagger}$ For Part VIII of this series, see ref 8.
}

and equatorial positions, respectively. Therefore, these monomers seem suitable for examining how the difference in spatial arrangement of such an electronegative bulky group on the carbon atom adjacent to the acetal carbon, a reaction center of nucleophilic substitution, affects the reactivity and stereoselectivity of the polymerization. Second, it is expected that the polymers derived from these monomers can be chemically modified in various ways to provide polysaccharide analogues with different functional groups.<smiles>BrC1CCC2OCC1O2</smiles><smiles>Br[C@H]1CC[C@H]2CO[C@H](C1)O2</smiles>

As for the polymerization of 4-bromo-6,8dioxabicyclo[3.2.1] octane, Hall et al. ${ }^{13}$ reported only briefly that phosphorus pentafluoride induced 
its polymerization in methylene chloride at $-78^{\circ} \mathrm{C}$ to produce a chloroform soluble polymer with an inherent viscosity of 0.1 . Although not described explicitly, the monomer used was apparently a mixture of 1a and 1e. In the present paper, we describe the polymerization of pure 1e and stereoisomer mixtures of $\mathbf{1 a}$ and $1 \mathbf{e}$ of different compositions, and discuss the reactivities of the two stereoisomers.

\section{EXPERIMENTAL}

\section{Materials}

4-Bromo-6,8-dioxabicyclo[3.2.1]octane was prepared by the procedure described by Brown et al. ${ }^{14}$ with slight modification: 3,4-Dihydro- $2 \mathrm{H}$-pyran-2carbaldehyde (acrolein dimer) was reduced with sodium borohydride in methanol to the corresponding alcohol. Subsequent bromination in carbon tetrachloride under slightly reduced pressure by an aspirator in order to eliminate hydrogen bromide gave the bromide in a yield of $85 \%$. bp $101-102^{\circ} \mathrm{C} /$ $4 \mathrm{mmHg}$. The product was composed of a mixture of axially and equatorially substituted stereoisomers 1a and 1e. However, it was difficult to isolate each component by conventional methods such as fractional distillation and liquid chromatography. Therefore, the mixture was treated with sodium hydride in 1,2-dimethoxyethane to remove $1 \mathrm{a}$ as 6,8-dioxabicyclo[3.2.1]oct-3-ene, and the unreacted 1e was recovered by fractional distillation. ${ }^{13} \mathrm{C}$ NMR data $\left(\mathrm{CDCl}_{3}\right)$ : 1a, $\delta 101.43 \mathrm{C}(5), 73.29 \mathrm{C}(1)$, $67.64 \mathrm{C}(7), 47.52 \mathrm{C}(4), 24.91$ and $24.44 \mathrm{C}(2)$ and $\mathrm{C}(3) ; 1 \mathrm{e}, \delta 102.41 \mathrm{C}(5), 72.74 \mathrm{C}(1), 68.57 \mathrm{C}(7), 49.86$ $\mathrm{C}(4), 30.41 \mathrm{C}(2)$, and $27.48 \mathrm{C}(3)$.

\section{Polymerization Procedure}

Polymerization was carried out in methylene chloride at temperatures between -90 and $0^{\circ} \mathrm{C}$. Boron trifluoride etherate, antimony pentachloride, antimony pentafluoride and trifluoromethanesulfonic acid were used as the initiators: A monomer solution was placed in a glass ampule, and after it was frozen in a liquid nitrogen bath, an initiator solution was added into the ampule. It was then evacuated, sealed off, and kept in a constant temperature bath. After a prescribed period of time, a small amount of pyridine was added to the reaction mixture to terminate the polymerization. The hetero- geneous mixture was poured into a large volume of methanol to precipitate a methanol-insoluble polymer. The amounts of a methanol-soluble oligomer and unreacted monomer were determined by gel permeation chromatography (column, JSP 101, $50 \mathrm{~cm}$; eluent, chloroform) and gas chromatography (column, butanediol succinate, $4 \mathrm{~m}$ ), respectively.

\section{Characterization}

${ }^{1} \mathrm{H}$ - and ${ }^{13} \mathrm{C}-\mathrm{NMR}$ spectra were recorded on JEOL MH-100 and JEOL FX-100 instruments working at 100 and $25 \mathrm{MHz}$, respectively. Deuteriochloroform and tetramethylsilane were used as the solvent and internal reference. Infrared spectra were taken with a JASCO A-3 spectrophotometer. Molecular weights of the polymers were measured by a Hewlet Packard vapor pressure osmometer on solutions in benzene at $37^{\circ} \mathrm{C}$ or by a Hitachi 634A gel permeation chromatograph (column, Shodex $80 \mathrm{M}, 1 \mathrm{~m}$ : eluent, chloroform).

\section{RESULTS AND DISCUSSION}

\section{Polymerization of 4(e)-Bromo-6,8-dioxabicyclo- [3.2.1] octane (1e)}

Polymerization of 1e was undertaken at different temperatures ranging from -90 to $0^{\circ} \mathrm{C}$. Table I presents some of the results of the polymerization of 1e. With antimony pentahalides and trifluoromethanesulfonic acid as initiators, 1e was polymerized to give a white powdery polymer at temperatures below $-60^{\circ} \mathrm{C}$, while an appreciable amount of methanol-soluble oligomeric materials were produced along with methanol-insoluble polymer at higher temperatures. Boron trifluoride etherate did not initiate the polymerization of $1 e$ at temperatures from -60 to $0^{\circ} \mathrm{C}$.

The polymers obtained with antimony pentahalides or trifluoromethanesulfonic acid at $0^{\circ} \mathrm{C}$ were soluble in chloroform, benzene, and $o$ dichlorobenzene, while those obtained at or below $-60^{\circ} \mathrm{C}$ were only partly soluble in hot chloroform. The poor solubility of the latter appears to arise from a higher stereoregularity of the polymers prepared at lower temperatures, although the X-ray diffraction pattern of these samples did not show crystallinity. The number average molecular weight of the chloroform-soluble part ranged from 1000 to 7800 , depending on the reaction conditions. The 


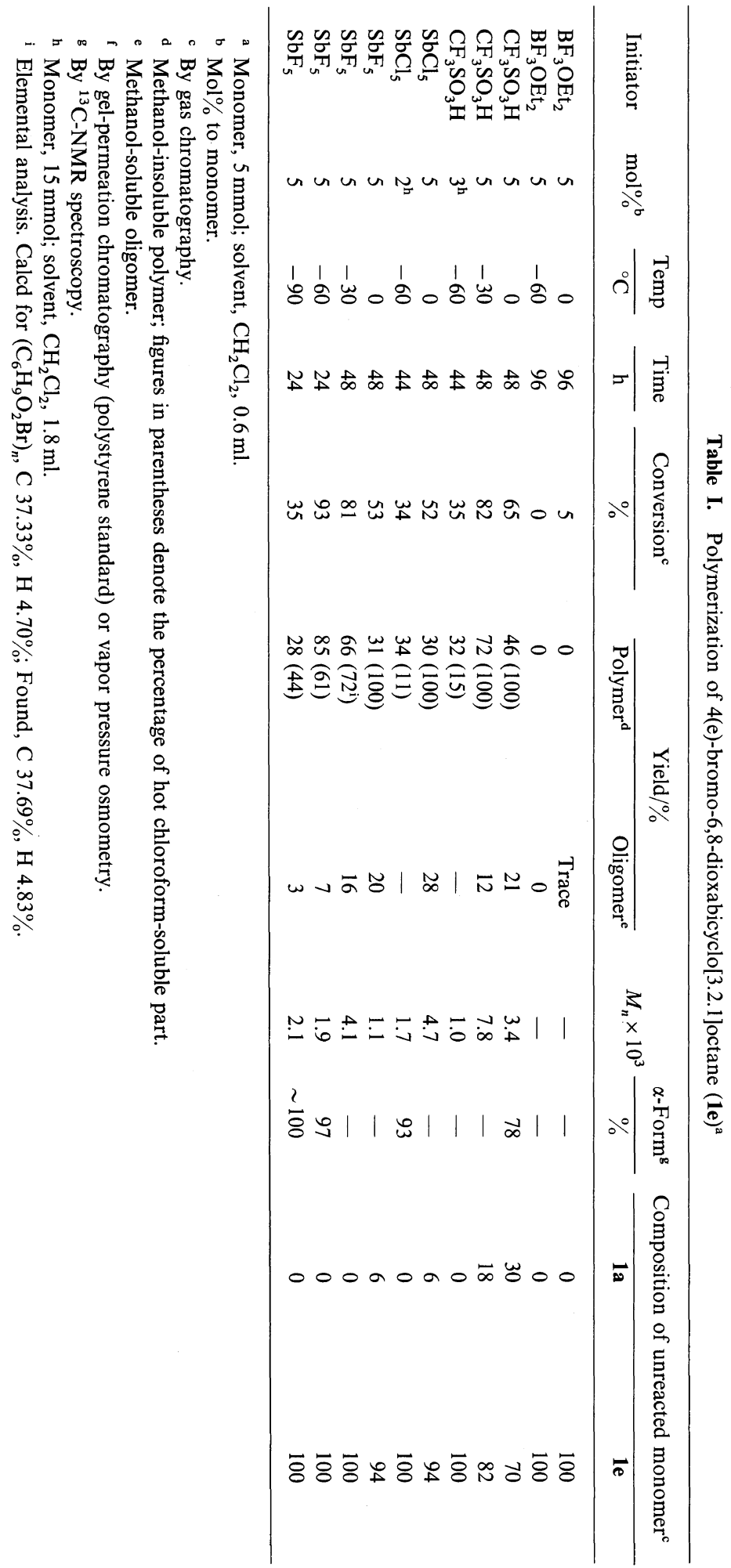

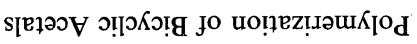


methanol-insoluble polymer melted at $128-139^{\circ} \mathrm{C}$ and began to decompose in air at about $190^{\circ} \mathrm{C}$. The major decomposition product was identified as monomer. Interestingly, when a polymer sample consisting entirely of 1e units with axially oriented bromine atoms was decomposed under vacuum at $220^{\circ} \mathrm{C}$, a monomer mixture of $1 \mathrm{a}$ and $1 \mathrm{e}(76: 24)$ was produced. This means that the isomerization of 1e units in a polymer chain to 1a units having an equatorially oriented bromine atom occurred appreciably during the thermal decomposition.

The figures in the last column of Table I represent the composition of unreacted monomer determined by gas chromatography. It is noteworthy that trifluoromethanesulfonic acid induced the isomerization of 1e to 1a at $-30^{\circ} \mathrm{C}$ or above. Antimony pentahalides also induced the isomerization, although to a lesser extent. In contrast, such isomerization did not take place with boron trifluoride etherate which was found incapable of initiating the homopolymerization of 1e. We suppose that the isomerization takes place on the polymer chain rather than on the monomer itself: The polymer of 1e takes a conformation in which the bromine atoms are axially oriented. Since this is energetically unfavorable, the configuration of the brominesubstituted carbon atom may be inverted under the influence of strong acids through a planar intermediate carbocation. Tetrahydropyran rings in the polymer chain are sufficiently flexible to allow the reaction to proceed. The configurationally inverted monomeric unit thus formed gives rise to 1a monomer, when it depolymerizes. Such an inversion of the configuration of the carbon atom bearing a bromine atom may also occur on the 1e monomer itself to give the 1a monomer. However, the reaction seems less likely to take place, because the relatively rigid bicyclic structure prevents the formation of a planar transition state and furthermore, 1a having a bulky bromine atom in the axial position should be thermodynamically unfavorable compared with 1e. The occurrence of the isomerization was confirmed by the ${ }^{13} \mathrm{C}-\mathrm{NMR}$ analysis of the polymers obtained at higher temperatures. This will be described in a later section.

Polymerization of Stereoisomer Mixtures of 4Bromo-6,8-dioxabicyclo[3.2.1] Joctane (1a and $\mathbf{1 b}$ )

Table II summarizes some of the results of the polymerization of stereoisomer mixtures of different compositions. The methanol-insoluble polymers obtained at $0^{\circ} \mathrm{C}$ were low molecular weight powdery materials, soluble in benzene, chloroform, and $o$ dichlorobenzene. With the decrease in polymerization temperature, the solubility of the methanol-insoluble polymers became markedly poor, and the polymers obtained below $-60^{\circ} \mathrm{C}$ were only partly soluble even in hot chloroform.

As described in the preceding section, le did not undergo polymerization in the presence of boron trifluoride etherate. On the contrary, the polymerization of stereoisomer mixtures of 1a and 1e took place with boron trifluoride etherate, and a considerable amount of 1e units was incorporated into a polymer chain. With antimony pentahalides and trifluoromethanesulfonic acid which induced the homopolymerization of $1 \mathbf{e}$, higher conversions to the polymer were attained, but the molecular weights of the polymers were significantly lower than those of the polymers obtained with boron trifluoride etherate. Irrespective of the polymerization conditions, 1a exhibited a higher reactivity than 1e as judged from the composition of the polymer determined by gas chromatographic analysis of the unreacted monomer.

\section{${ }^{13} \mathrm{C}-\mathrm{NMR}$ Analysis of Poly(3-bromotetrahydro- pyran-6,2-diyloxymethylene)}

Figure 1 shows the ${ }^{13} \mathrm{C}$-NMR spectrum of the polymer of 1e which was prepared at $-60^{\circ} \mathrm{C}$ with antimony pentafluoride, together with the assignments of the signals. The major signals $a^{\prime \prime}$ through $f^{\prime \prime}$ are due to the structural unit ( $\alpha$-form) in which the exocyclic acetal oxygen is axially oriented to the tetrahydropyran ring in a repeating unit. Beside these signals, there appear the minor signals $a^{\prime \prime \prime}$ through $f^{\prime \prime \prime}$ due to another structural unit ( $\beta$-form) in which the exocyclic acetal oxygen lies in the equatorial position of the tetrahydropyran ring in a repeating unit. Therefore, the fractions of the $\alpha$ - and $\beta$-forms in the polymer can be estimated from the relative areas of the wellseparated signal pairs such as $a^{\prime \prime}$ and $a^{\prime \prime \prime}$, and $f^{\prime \prime}$ and $f^{\prime \prime \prime}$.

It is noticeable in Figure 1 that the signals $a^{\prime \prime}, b^{\prime \prime}$, $c^{\prime \prime}$, and $e^{\prime \prime}$ are split into two peaks with different intensities. Similar splittings of the signals were more clearly observed in a ${ }^{13} \mathrm{C}$-NMR spectrum of poly(tetrahydropyran-2,6-diyloxymethylene), and they were confirmed to arise from different dyad 
Polymerization of Bicyclic Acetals

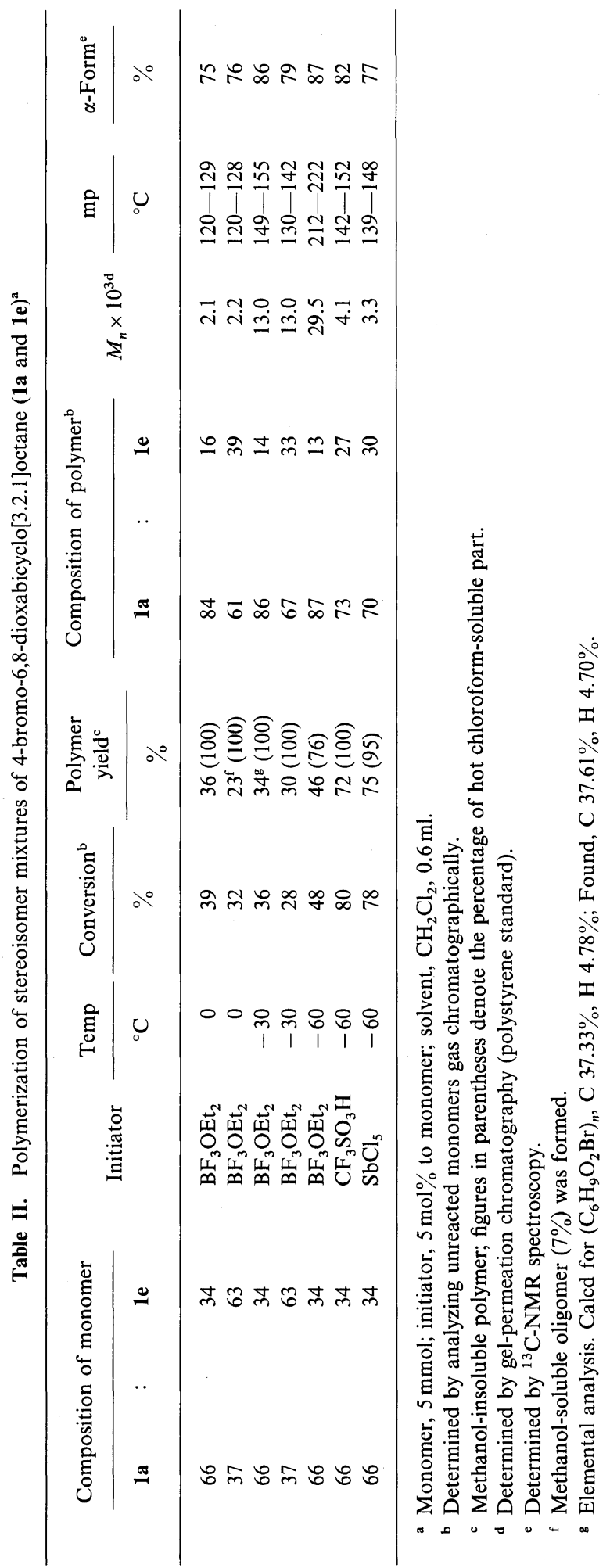




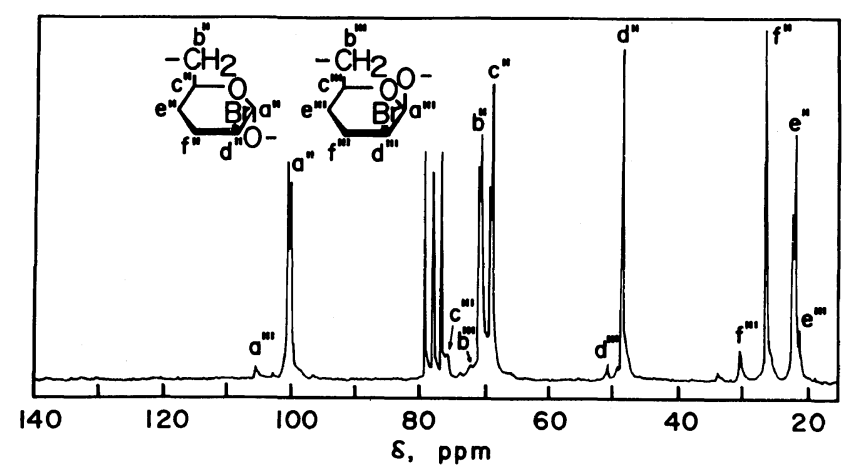

Figure 1. ${ }^{13} \mathrm{C}-\mathrm{NMR}$ spectrum of poly(3-bromotetrahydropyran-6,2-diyloxymethylene) prepared from 4(e)-bromo-6,8-dioxabicyclo[3.2.1] octane (1e) in $\mathrm{CH}_{2} \mathrm{Cl}_{2}$ at $-60^{\circ} \mathrm{C}$ with $\mathrm{SbF}_{5}$. Solvent, $\mathrm{CDCl}_{3}$; temp, $50^{\circ} \mathrm{C} ; 25 \mathrm{MHz}$; internal reference, tetramethylsilane.

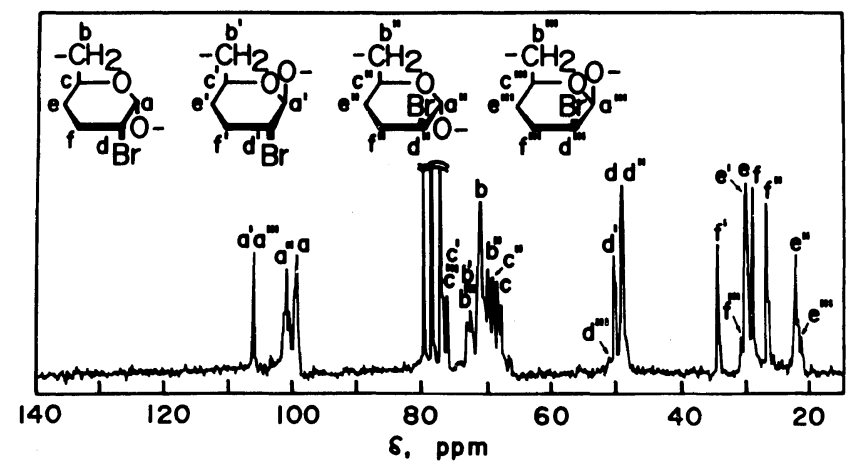

Figure 2. ${ }^{13} \mathrm{C}-\mathrm{NMR}$ spectrum of poly(3-bromotetrahydropyran-6,2-diyloxymethylene) prepared from 4(e)-bromo-6,8-dioxabicyclo[3.2.1] octane (1e) in $\mathrm{CH}_{2} \mathrm{Cl}_{2}$ at $0^{\circ} \mathrm{C}$ with $\mathrm{CF}_{3} \mathrm{SO}_{3} \mathrm{H}$. Solvent, $\mathrm{CDCl}_{3}$ : temp, $50^{\circ} \mathrm{C} ; 25 \mathrm{MHz}$; internal reference, tetramethylsilane.

placements of D- and L-monomeric unit along a polymer chain. ${ }^{6,7}$ By the analogy of the unsubstituted polymer having the identical backbone structure, it seems reasonable to assume that the splittings observed in the ${ }^{13} \mathrm{C}$-NMR spectrum in Figure 1 are ascribable to dyad tacticities, although definite assignments cannot be made at present.

As described in the foregoing section, the isomerization of 1e to 1a occurred to a considerable extent when the polymerization of 1e was carried out at $0^{\circ} \mathrm{C}$ with trifluoromethanesulfonic acid or antimony pentahalides as initiators. This was also demonstrated in the complicated ${ }^{13} \mathrm{C}-\mathrm{NMR}$ spectrum of the polymer of $1 \mathrm{e}$ prepared at $0^{\circ} \mathrm{C}$ with trifluoromethanesulfonic acid (Figure 2). Besides the signals due to the $\alpha$ - and $\beta$-forms of 1e units, $\left(a^{\prime \prime}\right.$ through $f^{\prime \prime}$ and $a^{\prime \prime \prime}$ through $f^{\prime \prime \prime}$, respectively), there appear the signals $a$ through $f$ and $a^{\prime}$ through $f^{\prime}$ assignable to the $\alpha$ - and $\beta$-forms of $1 \mathrm{a}$ units, respectively. Thus, four structural units coexist in this polymer, and the presence of the $\alpha$ - and $\beta$-forms of 1a units clearly indicates that the inversion of the configuration at the carbon atom bearing a bromine atom occurred during the polymerization. The assignments of signals due to the $\alpha$ - and $\beta$-forms of 1 a units were made on the basis of the ${ }^{13} \mathrm{C}$-NMR spectrum of a polymer predominantly consisting of 1a units.

Figure 3 gives the ${ }^{13} \mathrm{C}$-NMR spectrum of the polymer prepared from a stereoisomer mixture of 1a: $: 1 e=66: 34$ at $0^{\circ} \mathrm{C}$ with boron trifluoride etherate as the initiator. The polymer mainly consists of the $\alpha$ - and $\beta$-forms of 1a units, and hence their chemical shift values can be precisely determined. The ${ }^{13} \mathrm{C}$ NMR data of the four structural units $(2,4,6$, and 8) of poly(3-bromotetrahydropyran-6,2-diyloxy- 


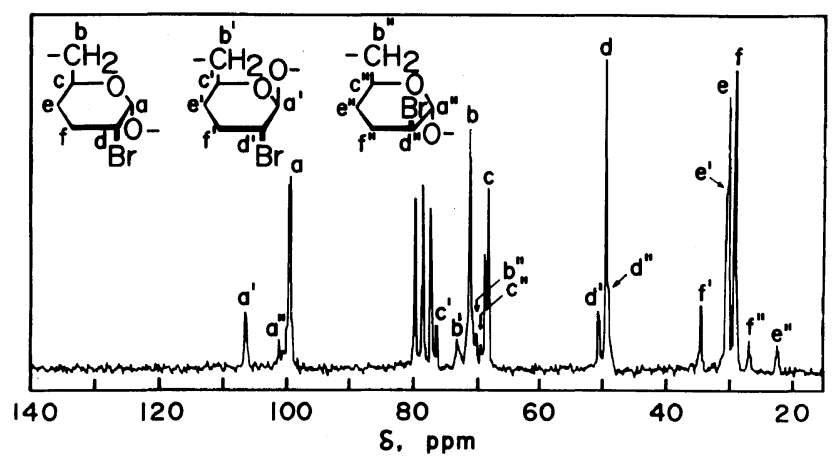

Figure 3. ${ }^{13} \mathrm{C}-\mathrm{NMR}$ spectrum of poly(3-bromotetrahydropyran-6,2-diyloxymethylene) prepared from a stereoisomer mixture of 4-bromo-6,8-dioxabicyclo[3.2.1]octane $(1 \mathrm{a}: \mathbf{1 e}=66: 34)$ in $\mathrm{CH}_{2} \mathrm{Cl}_{2}$ at $-30^{\circ} \mathrm{C}$ with $\mathrm{BF}_{3} \mathrm{Et}_{2} \mathrm{O}$. Solvent, $\mathrm{CDCl}_{3}$; temp, $50^{\circ} \mathrm{C} ; 25 \mathrm{MHz}$; internal reference, tetramethylsilane.

Table III. ${ }^{13} \mathrm{C}-\mathrm{NMR}$ chemical shift data for the four structural units of poly(3-bromotetrahydropyran6,2-diyloxymethylene)

\begin{tabular}{crccccc}
\hline & \multicolumn{6}{c}{ Assignment $^{\mathrm{a}}$} \\
\cline { 2 - 7 } unit & $\mathrm{a} \cdot$ & $\mathrm{b}$ & $\mathrm{c}$ & $\mathrm{d}$ & $\mathrm{e}$ & $\mathrm{f}$ \\
\cline { 2 - 7 } & & & & & & \\
\hline $\mathbf{2}$ & 97.57 & 69.61 & 66.96 & 48.50 & 29.74 & 28.66 \\
$\mathbf{4}$ & 104.19 & 71.48 & 74.72 & 47.36 & 29.95 & 34.08 \\
$\mathbf{6}$ & 99.29 & 69.78 & 68.18 & 48.12 & 22.23 & 26.57 \\
$\mathbf{8}$ & 104.23 & 71.42 & 73.17 & 50.56 & 21.39 & 30.63 \\
\hline
\end{tabular}

$*$<smiles>CCC1CCC(Br)C(OC)O1</smiles>
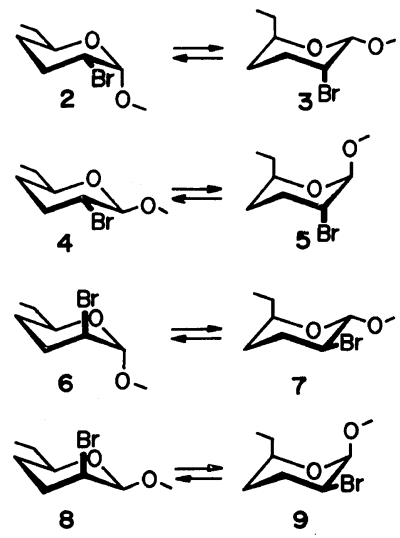

methylene) are listed in Table III.

Conformational free energies for $2,4,6,8$, and their flipped conformations $(\mathbf{3}, \mathbf{5}, \mathbf{7}$, and 9) were estimated from non-bonded interaction energies between substituents of the tetrahydropyran ring and anomeric interaction energies by the analogy of pyranose derivatives. ${ }^{15,16}$ The numerical parameters $\left(\mathrm{kJ} \mathrm{mol}^{-1}\right)$ for the calculation are: $\mathrm{O}^{\mathrm{ax}}-\mathrm{H}^{\mathrm{ax}}, 1.90$; $\mathrm{CH}_{2}{ }^{\mathrm{ax}}-\mathrm{H}^{\mathrm{ax}}, 3.75 ; \mathrm{CH}_{2}{ }^{\mathrm{ax}}-\mathrm{O}^{\mathrm{ax}}, 10.45 ; \mathrm{Br}^{\mathrm{ax}}-\mathrm{O}^{\mathrm{eq}}$ and $\mathrm{Br}^{\mathrm{eq}}-\mathrm{Br}^{\mathrm{ax}}, 1.45$; anomeric effect, $2.30 ; \Delta 2$ effect, 4.20. The results of the estimation are summarized in Table IV, together with the calculated equilibrium constants at $25^{\circ} \mathrm{C}$. In this estimation, it was assumed that the non-bonded interaction energies involving a bromine atom could be approximated by those involving an oxygen atom in the corresponding spatial positions.

As the data in Table IV show, the flipped conformations 3, 5, and 9 are of high energies and can safely be excluded. The structural unit 7 may be in conformational equilibrium with $\mathbf{6}$, but the former fraction must be very low. Therefore, it may be permissible to postulate that the polymer of stereoisomer mixtures of $\mathbf{1 a}$ and $1 \mathrm{e}$ is virtually composed of the four structural units, 2, 4, 6, and 8 . Actually, the structural unit $\mathbf{8}$, supposed to be the least component among these structural units, was not detectable in the ${ }^{13} \mathrm{C}$-NMR spectrum shown in Figure 3.

From the relative peak areas of $f, f^{\prime}$, and $f^{\prime \prime}$ in the expanded spectrum, the polymer obtained from a monomer mixture of $1 \mathbf{a}: 1 \mathrm{e}=66: 34$ at $-30^{\circ} \mathrm{C}$ with boron trifluoride etherate was found to consist of 2 $(76 \%), 4(16 \%)$, and $6(8 \%)$. The formation of the 
Table IV. Estimation of conformational free energy for possible structural units of poly(3-bromotetrahydropyran-6,2-

diyloxymethylene)

\begin{tabular}{|c|c|c|c|}
\hline \multirow{2}{*}{$\begin{array}{l}\text { Structural } \\
\text { unit }\end{array}$} & Free energy & \multirow{2}{*}{$\begin{array}{c}\text { Equilibrium } \\
\text { constant }\left(25^{\circ} \mathrm{C}\right)\end{array}$} & \multirow{2}{*}{$\frac{\text { Proportion }}{\%}$} \\
\hline & $\mathrm{kJ} \mathrm{mol}^{-1}$ & & \\
\hline 2 & 5.2 & \multirow{2}{*}{$K_{1}=1.9 \times 10^{-2}$} & 98 \\
\hline 3 & 15.1 & & 2 \\
\hline 4 & 3.8 & \multirow{2}{*}{$K_{2}=3.2 \times 10^{-3}$} & 100 \\
\hline 5 & 18.0 & & 0 \\
\hline 6 & 5.7 & \multirow{2}{*}{$K_{3}=1.0 \times 10^{-1}$} & 91 \\
\hline 7 & 11.3 & & 9 \\
\hline 8 & 7.5 & \multirow{2}{*}{$K_{4}=1.7 \times 10^{-2}$} & 98 \\
\hline 9 & 17.6 & & 2 \\
\hline
\end{tabular}

polymer consisting mainly of 1a units is understandable in view of the fact that the homopolymerization of 1e cannot be initiated by boron trifluoride etherate.

Reactivities of the Stereoisomers of 4-Bromo-6,8dioxabicyclo[3.2.1]octane (1a and 1e)

Unsubstituted 6,8-dioxabicyclo[3.2.1]octane readily undergoes cationic polymerization at low temperatures to give a stereoregular high molecular weight polymer in high yield..$^{6,7,13,17}$ As shown in Tables I and II, replacement of one of the methylene hydrogens on the $\mathrm{C}(4)$ atom by a bromine atom markedly reduces the polymerizability of the bicyclic acetal. This was also substantiated by the exclusive formation of a homopolymer of 6,8dioxabicyclo[3.2.1]octane in its attempted copolymerization with 1e. The reduced polymerizability of 1a and 1e compared with the unsubstituted parent compound is due to several factors, such as weaker nucleophilicity and lower ring-opening reactivity, and greater steric hindrance in the propagation reaction of $1 \mathrm{a}$ and 1e. As a measure of nucleophilicity, the basicity $\left(\mathrm{p} K_{\mathrm{b}}\right.$ value) has been frequently used. The $\mathrm{p} K_{\mathrm{b}}$ value of a mixture of 1a and 1e (50:50) was estimated to be $8.6_{4}$ from the shift value of methanol- $d_{1}$ in the IR spectrum of the monomer solution in benzene according to Gordy's method. ${ }^{18}$ (The $\mathrm{p} K_{\mathrm{b}}$ value of 6,8-dioxabicyclo[3.2.1] octane is $6.9_{4}{ }^{8}$ ) As for the ring-opening reactivity, the rate constant of acid-catalyzed hydrolysis provides a relative measure. Therefore, the dichloroacetic acid-catalyzed hydrolysis of a mixture of 1a and 1e was attempted in a mixed solvent of acetone- $d_{6}$ and deuterium oxide (volume ratio $3: 1$ ) at room temperature. ${ }^{8,19}$ The mixture of 1a and 1e was not hydrolyzed to a measurable extent even after a period of 30 days under the conditions where 6,8-dioxabicyclo[3.2.1]octane gave a first order rate constant of $5.0 \times 10^{-6}$ $\mathrm{s}^{-1.8}$ These findings can be related to the reduced polymerizability of $1 \mathrm{a}$ and 1e compared with that of the parent compound.

It is interesting to note here that 1,6-anhydro$2,3,4$-tri- $O$-benzyl- $\beta$-D-mannopyranose shows a higher reactivity than 1,6-anhydro-2,3,4-tri- $O$ benzyl- $\beta$-D-glucopyranose in their cationic copolymerization. ${ }^{20}$ The higher reactivity of the mannose derivative having an equatorial substituent on the carbon adjacent to the acetal carbon is in remarkable contrast to the aforementioned higher reactivity of $\mathbf{1 a}$ having an axial bromine atom on the same carbon in the polymerization of stereoisomer mixtures of $\mathbf{1 a}$ and 1e. The relative reactivities in the copolymerization of the anhydrosugar derivatives have been interpreted primarily in terms of eclipsed conformations during the transformation from ${ }^{1} \mathrm{C}_{4}$ conformation (oxonium ion) to ${ }^{4} \mathrm{C}_{1}$ conformation (polymer) and of relative stability of oxonium ions. ${ }^{20}$

The higher reactivity of $\mathbf{1 a}$ over $\mathbf{1 e}$, however, cannot be rationalized by these factors. Intuitively, it would appear that the axial bromine atom of a growing chain end of 1a unit, tentatively assumed to be D-enantiomer of 1a, gives rise to considerable steric hindrance when an incoming monomer, whether 1a or 1e, or D-enantiomer or L-enantiomer, approaches the partially positively charged acetal carbon of the terminal oxonium ion. In addition, CPK molecular model inspection reveals that when D-enantiomer of $1 e$ approaches the growing chain end in such a way as to minimize steric repulsion, electrostatic repulsion will arise between the bromine atom of the monomer and the lone pair electrons of the oxygen atom of the tetrahydropyran ring of the terminal unit (Scheme 1, upper left). Similar repulsion is expected to arise between the two bromine atoms of the growing chain end and incoming monomer when the L-enantiomer of 10 approaches the 

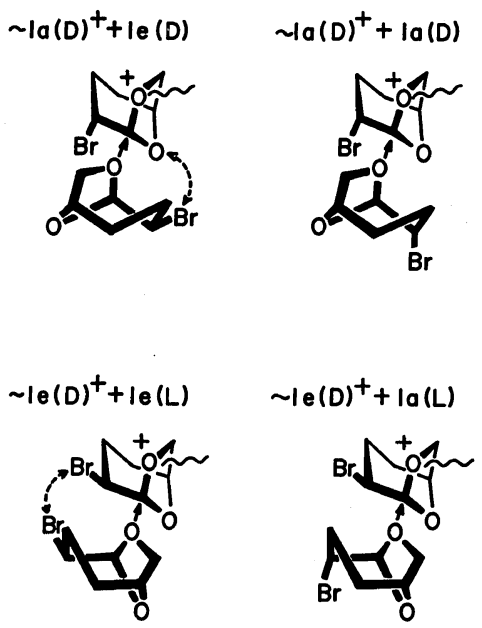

Scheme I.

acetal carbon of the oxonium ion. However, when the 1a monomer, whether D-enantiomer or Lenantiomer, approaches the oxonium ion, such an electrostatic repulsion seems unimportant, since the bromine atom of the incoming monomer can be considerably apart from both the oxygen atom of the tetrahydropyran ring and the bromine atom of the terminal oxonium ion (Scheme 1, upper right).

In the propagation reactions involving the $\mathrm{D}$ - or L-enantiomer of $1 \mathbf{e}$ and an oxonium ion of $1 \mathrm{e}$ unit tentatively assumed to be D-enantiomer of $\mathbf{1 e}$, electrostatic repulsion occurs between the bromine atom of the incoming monomer and the oxygen atom of the tetrahydropyran ring or the bromine atom of the oxonium ion, respectively (Scheme 1, lower left). In contrast to this, when the $\mathrm{D}$ - or $\mathrm{L}$ enantiomer of 1a approaches the oxonium ion, there is little if any repulsion since the distances between the bromine atom of the incoming monomer and the oxygen atom of the tetrahydropyran ring or the bromine atom of the terminal oxonium ion are sufficiently large (Scheme 1, lower right). At first glance, it seems likely that the polymerization of 1a having an axial substituent is unfavorable compared with that of its equatorially substituted counterpart 1e, but actually, the kinetical polymerizability of the latter seems to be considerably reduced by the electrostatic repulsions involved in the propagation described above. Furthermore, a thermodynamic factor must be taken into account. In the monomeric state, 1e with its equatorially oriented bromine atom is less sterically hindered and more stable than $1 \mathrm{a}$ with its axially oriented bromine atom. On the other hand, the polymer of 1e in which the predominant structural unit takes a conformation with its bromine atom in the axial position of the tetrahydropyran ring is energetically less stable than the polymer of $1 \mathbf{a}$ which consists of the structural unit having its bromine atom in the equatorial position. Thus, the enthalpy change from 1a to its polymer becomes more negative than that for 1e. Since the entropy change from monomer to polymer is supposed to be similar for both monomers, the thermodynamical polymerizability of 1a should be higher than that of 1 e.

In summary, the stereoisomers of 4-bromo-6,8dioxabicyclo[3.2.1]octane, 1a and 1e, undergo cationic polymerization at low temperatures to provide polyacetals with backbone structures similar to that of naturally occurring dextran. At relatively higher temperatures, epimerization of the acetal carbon of the polymer as well as isomerization of the stereoisomers occur, thus leading to a stereoirregular polymer. The axially substituted isomer $\mathbf{1 a}$ showed a higher polymerizability than the equatorially substituted isomer irrespective of the reaction conditions.

Acknowledgment. Financial support from the Ministry of Education, Science and Culture of Japan (Grant-in-Aid for Scientific Research No. 547090) is gratefully acknowledged.

\section{REFERENCES}

1. H. Sumitomo, M. Okada, and Y. Hibino, J. Polym. Sci., Polym. Lett. Ed., 10, 871 (1972).

2. M. Okada, H. Sumitomo, and Y. Hibino, Polym. J., 6, 256 (1974).

3. M. Okada, H. Sumitomo, and Y. Hibino, Polym. J., 7, 511 (1975).

4. M. Okada, H. Sumitomo, and S. Irii, Makromol. Chem., 178, 343 (1977).

5. M. Okada, H. Sumitomo, and H. Komada, Makromol. Chem., 179, 949 (1978).

6. H. Komada, M. Okada, and H. Sumitomo, Macromolecules, 12, 5 (1979).

7. M. Okada, H. Sumitomo, and H. Komada, Macromolecules, 12, 395 (1979).

8. M. Okada, H. Sumitomo, M. Kanie, and H. Komada, Makromol. Chem., 181, 2315 (1980).

9. M. Okada, H. Sumitomo, and H. Komada, Makromol. Chem., 179, 949 (1978). 
10. H. Komada, M. Okada, and H. Sumitomo, Makromol. Chem., 179, 2859 (1978).

11. M. Okada, H. Sumitomo, M. Hasegawa, and H. Komada, Makromol. Chem., 180, 813 (1979).

12. H. Komada, M. Okada, and H. Sumitomo, Makromol. Chem., 181, 2305 (1980).

13. H. K. Hall, Jr., and M. J. Steuck, J. Polym. Sci., Polym. Chem. Ed., 11, 1035 (1973).

14. F. Sweet and R. K. Brown, Can. J. Chem., 46, 2289 (1968).

15. S. J. Angyal, Aust. J. Chem., 21, 2736 (1968).

16. S. J. Angyal, "The Carbohydrates, Chemistry and
Biochemistry," W. Pigman and D. Horton, Ed., Academic Press, New York, 1972, p 202.

17. J. Kops, J. Polym. Sci., A-1, 10, 1275 (1972).

18. W. Gordy and S. C. Stanford, J. Chem. Phys., 7, 93 (1939); ibid., 8, 170 (1940); ibid., 9, 204 and 215 (1941).

19. H. K. Hall, Jr., F. DeBlauwe, L. J. Carr, V. S. Rao, and G. S. Reddy, J. Polym. Sci., Polym. Symp., No. 56, 101 (1976).

20. K. Kobayashi and C. Schuerch, J. Polym. Sci., Polym. Chem. Ed., 15, 913 (1977). 